\title{
Mammary gland growth and milk ejection in the agile wallaby, Macropus agilis, displaying concurrent asynchronous lactation
}

\author{
D. W. Lincoln* and Marilyn B. Renfree
}

School of Environmental and Life Sciences, Murdoch University, Western Australia 6150

Summary. Lactation was initiated and confined to the mammary gland to which the neonate attached at birth, and continued for about 360 days. The lactating gland continued to grow for over 200 days, increasing 7- to 10-fold in size between Days 50 and 250 . The young at these times weighed approximately 35 and $2500 \mathrm{~g}$ respectively. The young left the pouch permanently at 200-220 days, although they continued to suck intermittently for a further 160 days. Twenty-six days after evacuation of the pouch a second young was born and this attached to one of the three unused nipples. Thereby a second lactation developed in parallel to the previous one, but over 200 days in arrears.

The nipples of the non-lactating mammary glands were about $6 \mathrm{~mm}$ long and 2 $\mathrm{mm}$ in diameter: these increased to $>50 \mathrm{~mm}$ long and $4 \mathrm{~mm}$ in diameter at Day 100 of lactation. Each nipple contained 18-33 separate galactophores. Recordings were made of intramammary pressure in cannulated galactophores of wallabies under barbiturate anaesthesia. Bolus injections of $2-30 \mathrm{mU}$ oxytocin caused increases in intramammary pressure after a latency of 23-60 sec, and pressures peaked at 20-60 $\mathrm{mmHg}$ after $50-100 \mathrm{sec}$. Infusions of oxytocin produced multiple increases in intramammary pressure with peaks at intervals of about $4 \mathrm{~min}$.

The threshold dose of oxytocin for the induction of a mammary contraction increased from approximately 2 to $15 \mathrm{mU}$ oxytocin between Days 50 and 250 of lactation. Likewise, there was an increase in the latency to the onset of contraction and a decline in the peak pressure generated between early and late lactation. Injections of small doses of oxytocin induced contraction only of mammary glands in early lactation, whereas larger doses caused the contraction of both 'young' and 'old' glands.

The decline in oxytocin sensitivity during lactation permits milk ejection in response to small releases of oxytocin to be confined to the mammary gland to which the neonate is continuously attached. Conversely, the release of a large quantity of oxytocin, in response to the sucking of the juvenile at foot, would cause milk ejection in both lactating mammary glands.

\section{Introduction}

Mammals have evolved a number of diverse but highly successful reproductive strategies. Eutherian mammals at one extreme have evolved a complex placenta to permit a prolongation of pregnancy, while the marsupial mammals have elaborated a sophisticated pattern of lactation to permit the nourishment of a neonate that at birth is almost embryonic in form. The complexities of marsupial lactation have long been recognized (Collie, 1830; Morgan, 1833a, b), though we

* Present address: Department of Anatomy, The Medical School, University Walk, Bristol BS8 1TD, U.K. 
still have very little understanding of the control mechanisms involved. The red kangaroo (Macropus rufus) is the only species for which a substantial amount of information exists: milk production is confined to the mammary gland to which the neonate attaches, the volume of milk produced increases and the composition changes during lactation, and evacuation of the pouch leads to the birth of the next young and the development of a second lactation in parallel to the previous one (Sharman \& Calaby, 1964; Sharman \& Pilton, 1964; Lemon \& Barker, 1967; Griffiths, McIntosh \& Leckie, 1972). Thus at any one time the red kangaroo may support a dormant blastocyst in the uterus, a young in the pouch and a juvenile at foot, and display concurrent asynchronous lactation.

With most eutherian mammals very little milk can be obtained by the sucking of the young unless supported by an oxytocin-induced contraction of the myoepithelial cells surrounding the alveoli of the mammary gland. The neurohypophysis of the marsupial contains oxytocin, lysine vasopressin and phenypressin (Ferguson \& Heller, 1965; Chauvet, Hurpet, Chauvet \& Acher, 1980), and for several years oxytocin has been used to facilitate the collection of milk for analysis (Gross \& Bolliger, 1959). There is, however, no information on milk ejection per se for any marsupial, or any information on how milk ejection is organized in relation to concurrent asynchronous lactation.

We have therefore studied the growth and development of the mammary gland of the agile wallaby, Macropus agilis, and the intramammary pressure changes evoked by the injection and infusion of neurohypophysial peptides. The agile wallaby displays a reproductive pattern similar to that of the red kangaroo (Text-fig. 1), but is much smaller and more manageable in captivity.

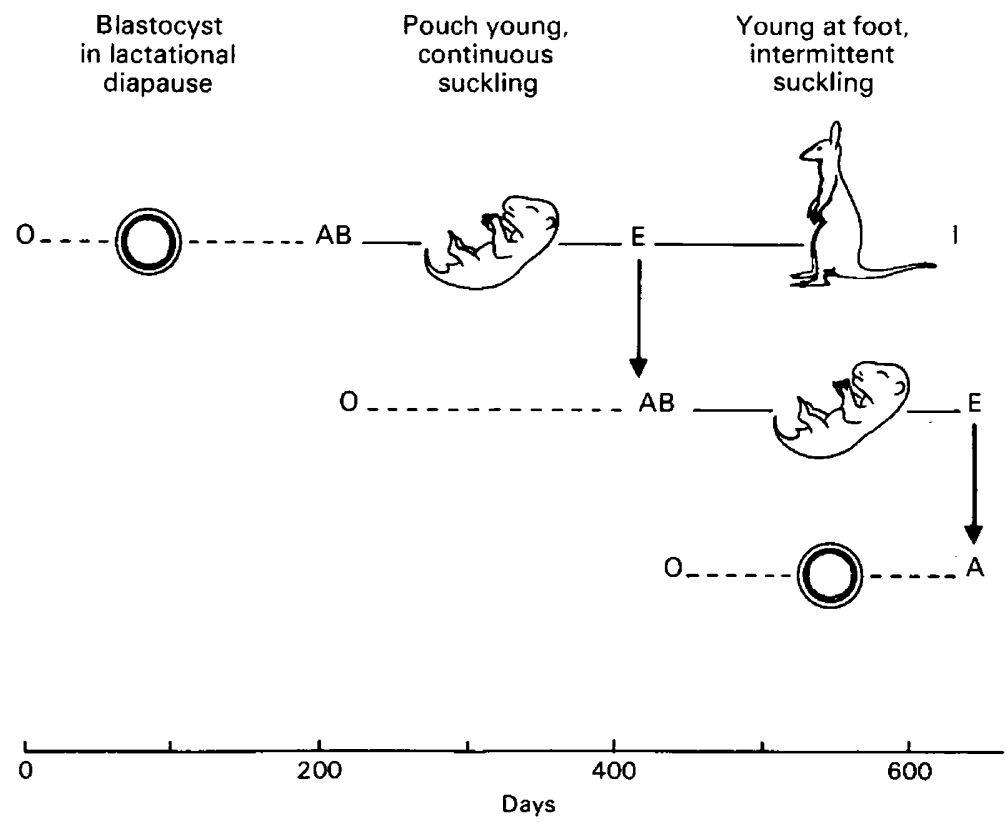

Text-fig. 1. The reproductive pattern of the agile wallaby, Macropus agilis. At any one time, the wallaby may have a blastocyst in the uterus, a young in the pouch and a dependant juvenile running at foot. Evacuation of the pouch is one of the key events; this leads to the immediate re-activation of the blastocyst in the uterus and the next young is born about 26 days later. $O$, ovulation; A, activation of blastocyst; B, birth; E, evacuation of the pouch by the young; I, independence. 


\section{Materials and Methods}

\section{Animals}

Experiments were conducted between June and August 1980 on a group of 32 agile wallabies (Macropus agilis), bred from stock that were a gift from the Perth Zoological Gardens. The animals were maintained in grassed paddocks in the Native Fauna Research Unit of Murdoch University, Western Australia, and were provided with lucerne hay and oats as supplementary feed when required. Murdoch University is several hundred miles south of the current range of the agile wallaby in northern Australia and New Guinea but, as Merchant (1976) found, the wallabies thrived in captivity in these conditions. All animals were dipped (Dizon-80; Cooper, Australia) and drenched (Thibenzole: Merck, Sharp \& Dohme, Australia) in March 1980 for the control of parasites. Animals were captured by long-handled circular nets some hours before required for experiments. Great care was necessary to avoid injuries to the animals (and personnel); the animals were extremely nervous despite routine handling and would, if agitated, run at speed into fences or each other.

When placed in thick sacks the wallabies immediately became docile, and were thereafter easy to handle if the heads were kept covered. The pouch young were removed, and the head, tail and pes length were determined. From these measurements the ages of the young were estimated from the standards published by Kirkpatrick \& Johnson (1969).

\section{Surgery}

Adult female wallabies $(10-15 \mathrm{~kg})$ with pouch young were anaesthetized with pentobarbitone sodium via a lateral tail vein. After about $2 \mathrm{~h}$ of anaesthesia, incremental doses of $0.5 \mathrm{ml}$ pentobarbitone sodium (BDH) made up in $0.9 \%(\mathrm{w} / \mathrm{v}) \mathrm{NaCl}$ to a solution of $62 \mathrm{mg} / \mathrm{ml}$ were given at intervals of $10 \mathrm{~min}$ in an attempt to maintain a uniform level of sedation. Body temperature was maintained at $35^{\circ} \mathrm{C}$, and the trachea was intubated at the first sign of respiratory distress. The left external jugular vein or the tail vein opposite to that used for the administration of the anaesthetic was cannulated towards the heart for the injection of peptides and drugs.

\section{Recording of intramammary pressure}

The pouch of the anaesthetized wallaby was retracted to expose the four mammary glands, and the dimensions of the lactating gland or glands and nipples were determined using callipers. A ligature was then placed about $4 \mathrm{~mm}$ back from the tip of the nipple of the lactating gland and tied just tight enough to prevent milk escaping after an injection of oxytocin. This ligature was then used to extend the nipple gently to about $70 \mathrm{~mm}$, thereby straightening the galactophores within. A longitudinal incision of about $10 \mathrm{~mm}$ was made midway down the nipple and, under a low-power operating microscope, the fascia surrounding the many galactophores was gently teased apart. Immediately before cannulation, an i.v. oxytocin injection of about $10 \mathrm{mU}$ was given to distend the galactophores with milk. Cannulation of individual galactophores was achieved by the insertion of a 25 -gauge needle about $6 \mathrm{~mm}$ along the duct. The needle was mounted on a ball coupling to permit free movement and connected via a flexible tube to a pressure transducer mounted level with the mammary gland. Before insertion, the cannula and transducer were completely filled with $1 \%$ sodium citrate and calibrated against a fixed head of water. The output from the transducer was plotted on a rectilinear chart recorder. When opportunities permitted, simultaneous pressure recordings were obtained from two galactophores, either in the same nipple or from 'old' and 'young' lactating mammary glands in the same animal. 


\section{Hormone administration}

Oxytocin (Syntocinon: Sandoz, U.K.), arginine-vasopressin (Sigma, U.S.A.) and lysinevasopressin (Sigma, U.S.A.) were prepared in suitable dilutions in $0.9 \%(\mathrm{w} / \mathrm{v}) \mathrm{NaCl}$ to permit bolus injections of $0.5-1.5 \mathrm{ml}$ or infusions of $0.5-1.5 \mathrm{ml} / \mathrm{min}$ to be given. Bolus injections were, unless otherwise specified, given at intervals of $10 \mathrm{~min}$, and always $1 \mathrm{~min}$ in advance of any supplementary dose of anaesthetic. Injections of pentobarbitone sodium during periods of oxytocin infusion caused a transitory fall in intramammary pressure and so supplementary injections of anaesthetic were avoided during infusions.

\section{Results}

\section{Growth of mammary gland and nipple}

All female wallabies that were lactating carried a pouch young, and these young were all firmly attached to the nipple when aged at 80 days or less. Twelve of the 18 females displayed two lactating mammary glands, one supporting the pouch young and the other presumably feeding an older sibling running at foot. The colony contained only 8 juveniles of $<1$ year of age. Lactation appeared to alternate from side to side, as all examples of double lactation involved one gland on either side. On the other hand, there was a slight preference for the young to attach to the upper $(n=20)$ rather than the lower nipples $(n=12)$.

An index of mammary growth was obtained by measuring the length and breadth of the gland as seen from the pouch (Text-fig. 2). Maximum gland size was not attained until the young had left the pouch, i.e. after 200 days. Whilst it was not possible to determine the lactational age of the mammary glands supporting young at foot with accuracy, it was noticeable that the very largest mammary glands were all found in association with a second lactating gland to which a neonate was attached. This suggests that maximum gland size occurs between 200 and 250 days. The increase in gland size depicted in Text-fig. 2 is two-dimensional and underestimates the increase in gland volume. The mammary glands of 7 autopsied wallabies were weighed: gland weight increased 7- to 10 -fold between Days 50 and 250 of lactation, the young at these times weighing approximately 35 and $2500 \mathrm{~g}$, respectively.

The nipple to which the $\sim 600 \mathrm{mg}$ neonate attached shortly after birth underwent a most dramatic increase in size, first increasing in length (Text-fig. 2) and then later in diameter. Nipples of non-lactating mammary glands, excluding those regressing from a previous lactation, were $6.0 \pm 2.3$ (s.d.) $\mathrm{mm}$ in length $(n=34)$. Within 10 days of the attachment of the young the nipple had increased 4-fold in length and by 100 days had reached a maximum length of 40-50 $\mathrm{mm}$, measured after the young had been detached and the nipple allowed to relax. The nipples of the lactating glands were extremely elastic; they would stretch to over $70 \mathrm{~mm}$ when pulled by the young and contract to $<25 \mathrm{~mm}$ when pinched with forceps or gently rolled between the fingers and released. Maximum nipple diameter of 4-5 $\mathrm{mm}$ was reached by about 100 days, and the dimensions of the nipple by Day 100 were identical to those of the previous lactation now aged $\geqslant 300$ days. From Day 80 the pouch young spends periods detached from the nipple.

Each nipple contained a mean of 22 galactophores (range 18-33). These opened in a random array over the terminal $3 \mathrm{~mm}$ of the nipple and each opening was marked by a ring of slightly pigmented cells. The galactophores were about $400 \mu \mathrm{m}$ in diameter when distended with milk. The walls of the galactophore appeared to be composed of fibro-elastic tissue rather than muscle: they were thin and transparent and collapsed in a Z-folded pattern when the nipple was allowed to contract. The nipples did not contain a tight sphincter and milk frequently leaked from the tip after the intravenous injection of oxytocin $(5-20 \mathrm{mU})$. 


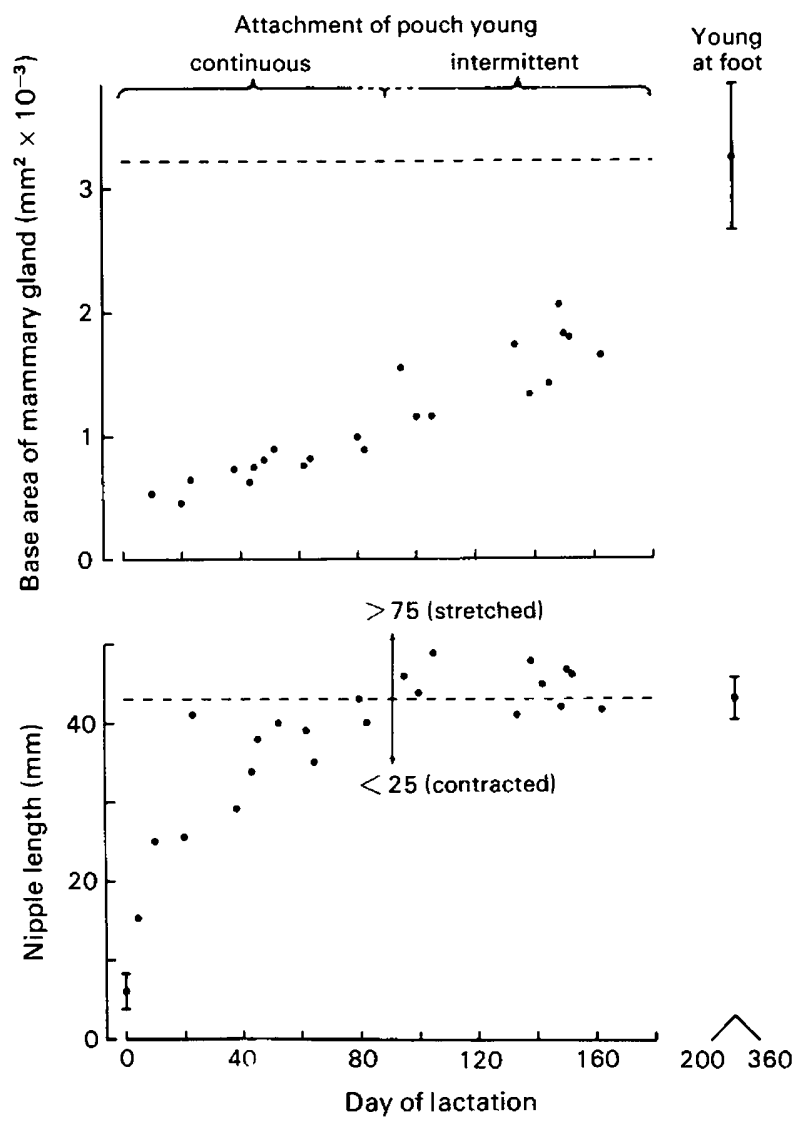

Text-fig. 2. Growth of the lactating mammary gland of the agile wallaby. The size of the mammary gland is presented as the base area of the gland as measured from the pouch. The length of the nipple was determined after the pouch young had been detached and the nipple allowed to relax. When a pouch young was present, the lactational 'age' of the mammary gland on which it was feeding was estimated from the size of the young and the previous history of the animal. The data for 12 wallabies with a presumed young at foot have been grouped (mean \pm s.d.). The horizontal broken lines represent the mean size and nipple length of the mature mammary gland.

\section{Mammary contractions induced by oxytocin}

The intravenous injection of oxytocin in doses of $2 \mathrm{mU}$ or greater caused dramatic increases in intramammary pressure. The latency to the onset of the pressure wave, the peak pressure and the duration of the response were related to the stage of lactation and the dose of hormone administered (Text-figs 3-7). Simultaneous recordings of pressure from separate galactophores within one nipple yielded almost identical responses (Text-fig. 5a), whilst simultaneous recordings from galactophores of glands at different stages of lactation in the same wallaby revealed marked differences (Text-fig. 6).

Response of mammary glands 0-100 days of lactation. The threshold dose of oxytocin for the induction of a recordable pressure change in these 'young' glands was 1-3 mU, and a maximum pressure response of $40-60 \mathrm{mmHg}$ was obtained with injections of $10-15 \mathrm{mU}$ (Text-fig. 6). No difference was observed between bolus injections given into the tail vein and those given into the external jugular vein. The latency to the onset of the pressure response was 23-30 sec with injections of $10 \mathrm{mU}$ oxytocin or more; this latency increased to $40-60 \mathrm{sec}$ with 


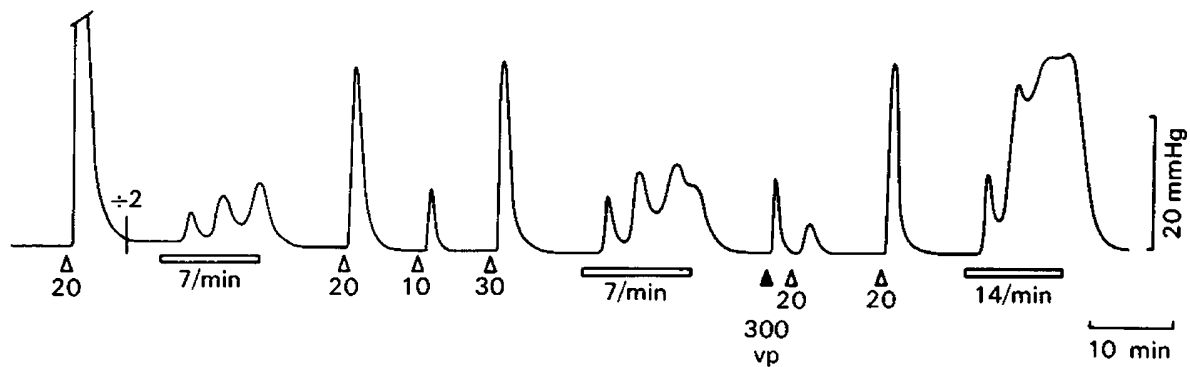

Text-fig. 3. An intramammary pressure recording from a single galactophore of a mammary gland at Day 80 of lactation in an agile wallaby to illustrate the response to intravenous injections (triangles) and infusions (bar) of oxytocin and arginine vasopressin (vp) in the doses indicated $(\mathrm{mU})$. The animal was anaesthetized with pentobarbitone sodium and the pouch young removed.

smaller doses. The pressure waves peaked at $50-100 \mathrm{sec}$ and baseline conditions returned after $100-300 \mathrm{sec}$ (Text-fig. 4).

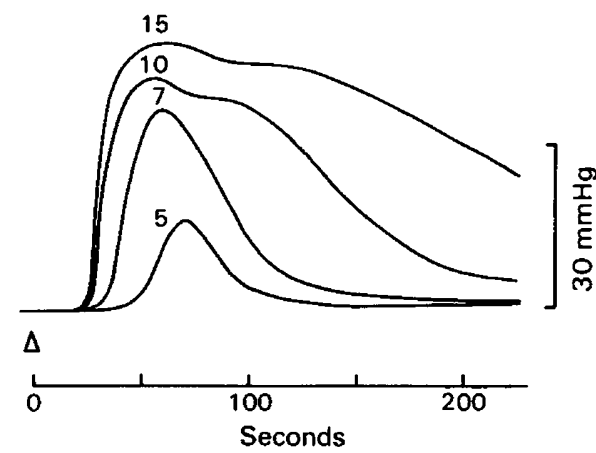

Text-fig. 4. Intramammary pressure recordings from a galactophore of a mammary gland at Day 100 of lactation to illustrate the latency and pattern of contraction evoked by the i.v. injection $(0 \mathrm{sec})$ of different doses of oxytocin.

Response of mammary glands over 200 days into lactation. The age of these glands in terms of lactation could not be determined with accuracy since there was no information available concerning the birth of the young that had initiated the lactation. For the purposes of Text-figs 5 and 6 such glands were taken to be 210 days further into lactation than the gland to which the pouch young was attached. These 'older' glands were much less sensitive to oxytocin and produced lower peak pressures. The threshold dose of oxytocin for the production of a measurable contraction was $10-15 \mathrm{mU}$ (Text-figs 5 and 6) and a dose in excess of $30 \mathrm{mU}$ was required to elicit a maximum contraction of $20-30 \mathrm{mmHg}$. The latency to the onset of the contraction was 45-60 sec with large doses of oxytocin, and frequently much longer. This difference in latency was so marked that in some double recordings the pressure wave of the 'young' gland had started to decline before that of the 'older' gland had commenced. A latency of less than $30 \mathrm{sec}$ to the onset of the contraction in the 'older' gland was obtained when a second oxytocin injection was given before the pressure response to a previous injection had totally subsided.

Mammary glands between 100 and 200 days of lactation displayed responses to oxytocin that were intermediate between the extremes just described. 

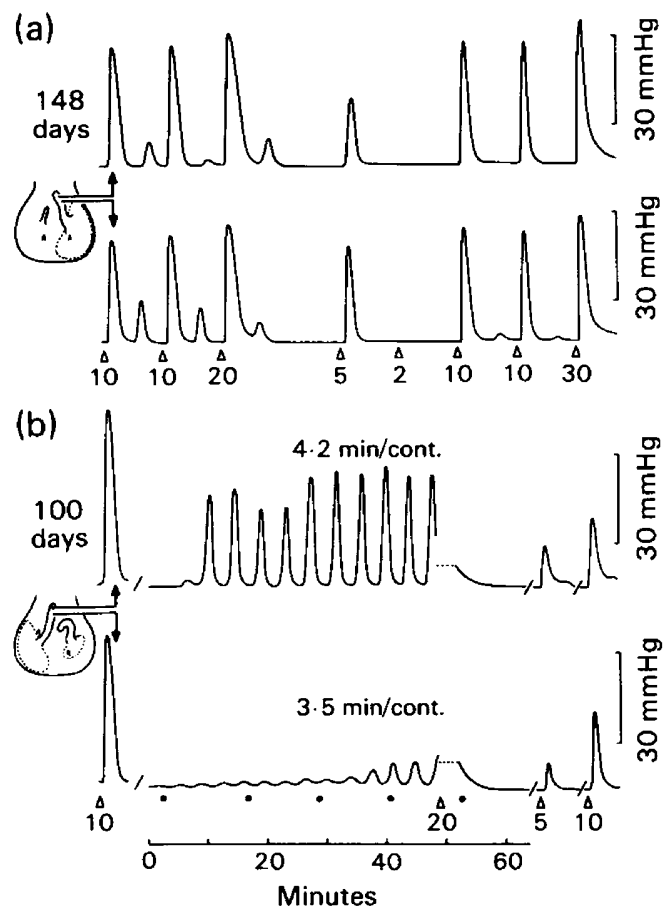

Text-fig. 5. Simultaneous recordings of intramammary pressure from two galactophores in a single nipple of a lactating mammary gland of an agile wallaby (a) at Day 148 and (b) at Day 100 of lactation in response to bolus injections of oxytocin in the doses indicated (mU). In (b) spontaneous contractions were recorded in the absence of any experimental manipulation, the frequency being greater in one duct than the other. These contractions were abolished after milk had been allowed to escape from the ducts $(\ldots)$ following the injection of $20 \mathrm{mU}$ oxytocin. Supplementary doses of $0.5 \mathrm{ml}$ pentobarbitone sodium $(62 \mathrm{mg} / \mathrm{ml})$ were given at 10 -min intervals ( ) to maintain anaesthesia; these were unrelated to the observed contractions.

\section{Infusion of oxytocin and spontaneous mammary contractions}

The infusion of oxytocin in doses of $3.5-17 \mathrm{mU} / \mathrm{min}$ induced a series of mammary contractions with peaks at intervals of about $4 \mathrm{~min}$ (Text-fig. 3). There was considerable variation in the response. In some animals the response consisted of a series of waves of increasing pressure, whilst in others there was an initial contraction of large amplitude followed by waves of decreasing size. Less frequently a tetanic contraction was observed in which peak pressure was sustained for several minutes during the early part of the infusion.

After several hours of recording, spontaneous contractions commonly developed with a periodicity similar to that produced by an infusion of oxytocin. Such contractions were not synchronized between galactophores within the same nipple (Text-figs 5 and 6), suggesting that they were not driven by a pulsatile release of endogenous oxytocin. Less frequently such contractions would cease spontaneously. Injections of adrenaline hydrochloride (50-100 $\mu \mathrm{g}$, i.v.) extinguished such contractility for short periods $(<6 \mathrm{~min})$ and totally abolished the response of the mammary gland to exogenous oxytocin (10-20 mU). A more effective way of circumventing the spontaneous contraction was to allow milk to escape from the cannulated teat duct (Text-fig. $5 b)$. 


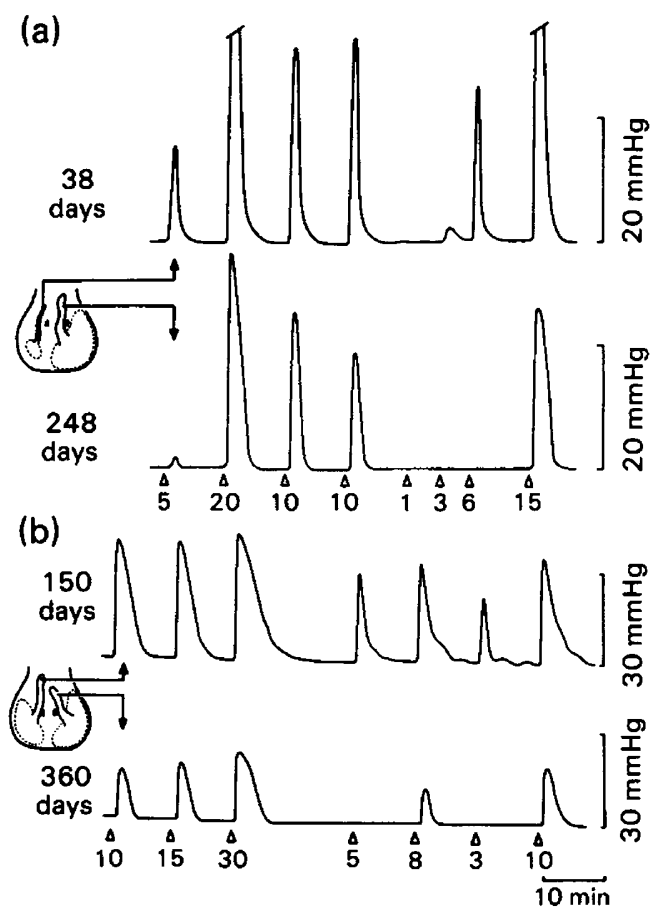

Text-fig. 6. Simultaneous recordings of intramammary pressure from galactophores of mammary glands at different stages of lactation (a, 38 and 248 days; b, 150 and 360 days) in the same agile wallaby. The doses of oxytocin injected $(\mathrm{mU})$ are indicated. The 'younger' gland of each pair generated higher peak pressures and responded to lower doses of oxytocin.
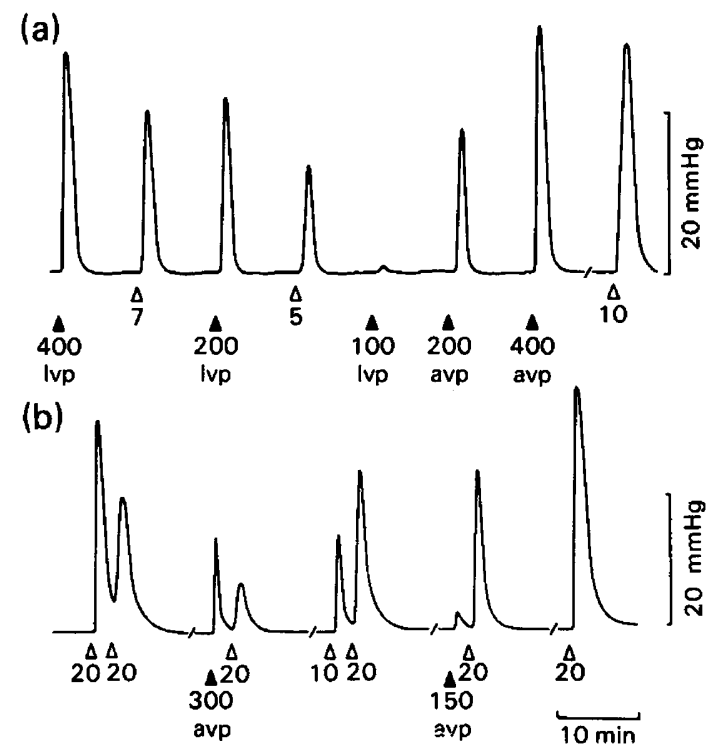

Text-fig. 7. Intramammary pressure recordings from two agile wallabies (a) at Day 146 and (b) at Day 80 of lactation. In (a) the response evoked by lysine (lvp) and arginine (avp) vasopressin is compared with that of oxytocin $(\Delta)$. In (b) the responses to injections given 90 -sec apart are presented. The doses indicated $(\mathrm{mU})$ were given i.v. 


\section{Response of the mammary gland to arginine and lysine vasopressin}

Both arginine- and lysine-vasopressin elicited mammary contractions, but only when given in doses 30 times greater than that of oxytocin (Text-figs 3 and 7). The vasopressin-induced contractions were slightly more abrupt in onset and terminated more quickly than oxytocin-induced contractions of similar amplitude.

The interval of 10 min between oxytocin injections, as depicted in Text-figs 3,5 and 6, was calculated to avoid one injection reducing the response to the next injection. As shown in Text-fig. 7, injections of oxytocin at an interval of $90 \mathrm{sec}$ resulted in a substantial reduction in the contraction elicited by the second injection. Injections of vasopressin, whilst causing only a small mammary contraction, caused a large reduction in the response to an injection of oxytocin given $90 \mathrm{sec}$ later (Text-fig. 7).

\section{Discussion}

The mammary gland of the agile wallaby, like that of other species of the genus Macropus displays a remarkable degree of autonomy. Lactation is confined to the gland to which the neonate attaches, and the gland continues to grow for at least 200 days. What growth represents in terms of an increase in gland volume has not been determined. Each gland appears to contain over 20 separate lobes, as indexed by the number of galactophores, and although growth could represent the recruitment of more segments of the gland as the needs of the young developed, the number of milk-filled galactophores was the same at Days 50 and 250. We therefore conclude that the enormous increase in gland size relates to an increase in alveolar tissue as proposed by Griffiths et al. (1972) for the red kangaroo.

The nipples of the agile wallaby stretch to an extraordinary degree, and for this one can see two advantages: (1) the young can feed from almost any position in the pouch and (2) the danger of accidental detachment during maternal grooming or the sucking of the older sibling is reduced. The pouch young were frequently seen grasping the nipple with alternate forelimbs. The advanced development of these limbs at birth would appear to be an adaptation to facilitate entry into the pouch, although the vigour with which they grasp the nipple could serve to stimulate milk ejection or to aid in milk removal.

There are reports that kangaroos in captivity will occasionally suckle young other than their own (Merchant \& Sharman, 1966), and this could be the reason why our colony contained more wallabies with mammary glands in advanced lactation than there were juveniles present. There does, however, appear to be a second possibility whereby lactation might be maintained after a young at foot has been lost. During the second half of their pouch life the young are of sufficient size to feed from the nipple of the mammary gland that originally raised the older sibling. Pouch young are remarkably efficient in attaching themselves to the nipples, which could indicate the presence of cues such as pheromones, but it is not known whether the young always re-attach to the same nipple, since the nipples of both lactating glands are at this time of the same dimensions. It would be interesting to separate wallabies with pouch young of 100 days from their young at foot and study the subsequent development of the two mammary glands.

The present results clearly indicate that oxytocin is as important to the marsupial as it is to the eutherian mammal. On a body weight basis the wallabies responded to much lower doses of oxytocin than do rabbits (Harris, Manabe \& Ruf, 1969) and rats (Lincoln, Hill \& Wakerley, 1973), and generated 8 times the intramammary pressure. In the rat and rabbit, vasopressin has $25 \%$ of the milk-ejecting activity of oxytocin (Berde \& Boissonnas, 1968). The corresponding figure for the agile wallaby is about $3 \%$, which suggests that the receptors of the wallaby mammary gland can discriminate more clearly between these closely related peptides. The efficacy of the response to vasopressin is thus low, but vasopressin binding to the oxytocin 
receptors may be appreciably greater as evidenced by the much greater reduction caused by vasopressin in the response to a follow-up injection of oxytocin (Text-fig. 7). On the other hand, the basic dose-response curve to oxytocin is very similar in eutherian and marsupial species, and is characteristically very steep. Oxytocin gives no response $(2 \mathrm{mU})$ or a full contraction $(10 \mathrm{mU})$ in an agile wallaby in early lactation; the corresponding figures for a mammary gland in late lactation are 6 and $30 \mathrm{mU}$. These comparisions between eutherian and marsupial species are summarized in Table 1.

Table 1. A comparison of the characteristics of milk ejection in marsupial and eutherian mammals

\begin{tabular}{lccc}
\hline & \multicolumn{2}{c}{ Agile wallaby } & \\
\cline { 2 - 3 } & $\begin{array}{c}\text { Early } \\
\text { lactation }\end{array}$ & $\begin{array}{c}\text { Late } \\
\text { lactation }\end{array}$ & $\begin{array}{c}\text { Rat and } \\
\text { rabbit }\end{array}$ \\
\hline $\begin{array}{l}\text { Peak intramammary pressure at milk ejection (mmHg) } \\
\text { Threshold dose of oxytocin for the production of a recordable } \\
\text { contraction (mU/kg body wt) }\end{array}$ & 60 & 20 & 10 \\
$\begin{array}{l}\text { Minimum frequency of electrical stimulation of oxytocin-producing } \\
\text { neurones for induction of milk ejection (Hz) }\end{array}$ & 0.2 & 1 & 1 \\
$\begin{array}{l}\text { Effectiveness of the teat sphincter to prevent the escape of milk } \\
\text { Milk ejection response to vasopressin (vasopressin to oxytocin ratio) }\end{array}$ & $\begin{array}{c}4.5 \\
\text { Poor } \\
30: 1\end{array}$ & $\begin{array}{c}25 \\
\text { Good } \\
4\end{array}$ \\
\hline
\end{tabular}

Another difference between 'young' and 'old' glands is the apparent decline in oxytocin sensitivity. The slope of the dose-response curve to oxytocin places the mammary contraction close to an 'all-or-none' response and it is unlikely that partial responses are due to only a proportion of the myoepithelial cells being activated with stronger contractions being promoted by the recruitment of more muscle elements. The contractions observed suggest something more akin to electrotonic spread of a contraction through the gland. In 'young' glands the myoepithelial cells are perhaps better coupled and thereby permit the development of an effective contraction in response to a lower oxytocin signal. In 'older' and much larger glands the myoepithelial cells may have less contact and electrotonic spread may be less effective, thus accounting for the much longer latencies observed. Indeed, contractions in one part of the mammary gland would be totally ineffective in generating milk ejection if balanced by passive distension elsewhere. Such a situation could account for the invariably more effective evocation of milk ejection by pulsatile injection of oxytocin than by an infusion of the same amount of the peptide. Multiple contractions in response to bolus injections or infusions of oxytocin and rhythmic contractions during engorgement of the mammary gland with milk are features of smooth muscle contractility in which the cells are electrically coupled (Text-fig. 3). Such multiple contractions as were recorded could be an artefact created by using a closed system from which milk cannot escape as it would during the sucking of the young. On the other hand, such contractility could be quite effective in 'pumping' milk into young during the early stages of pouch life. Indeed, this could account for lactation continuing for some weeks after denervation of the mammary gland of the tammar wallaby (Macropus eugenii) (Renfree, 1979).

Although these studies do not establish unequivocally how milk ejection is organized in concurrent asynchronous lactation, a clear strategy does emerge. In early lactation (e.g. Day 40) the very 'small' pouch young $(30 \mathrm{~g})$ could not generate a substantial sensory stimulus to activate a milk-ejection reflex. However, we have already shown that milk ejection can be evoked by prolonged low-frequency electrical stimulation $(4-5 \mathrm{pulses} / \mathrm{sec}$ ) of the putative oxytocinergic neurones in the basal hypothalamus (Lincoln \& Renfree, 1981). This contrasts with the minimum effective stimulation frequency of $25 \mathrm{pulses} / \mathrm{sec}$ in the rat and rabbit (Harris et al., 1969; Lincoln et al., 1973). Thus, a small increase in the firing of the oxytocin cells in the wallaby in response to the activities of the minute pouch young could produce a low but 
sustained release of oxytocin. Such a release would cause a rhythmic pattern of milk ejection in the 'young' (oxytocin-sensitive) mammary gland, and the high pressures generated would, in the absence of a tight teat sphincter, result in milk being 'pumped' into the attached young. The 'older' (oxytocin-insensitive) mammary gland would not contract and spill milk into the pouch. Conversely, in late lactation (e.g. Day 250) the young at foot $(2500 \mathrm{~g})$ must produce a large sensory stimulus when it sucks at the nipple, leading to a correspondingly larger acceleration in the firing of the oxytocinergic neurones and hence release sufficient oxytocin to induce contraction of the gland. This oxytocin surge would have little effect on the 'young' gland if that gland was already contracting, because the pressure response reaches a plateau at about 60 $\mathrm{mmHg}$ and additional oxytocin will not elevate this pressure. If the 'young' gland is not contracting the effect of a milk ejection triggered by the young at foot will be simply to give the pouch young an additional meal, and because the young is continuously attached at this time milk will not be extruded into the pouch.

We acknowledge the financial support of the Australian Research Grants Committee (D.I. 7515759), the National Institutes of Health (HD-09387) and the Royal Society for a Commonwealth Bursary. We thank Kate Creed for the use of recording apparatus, and our many colleagues who assisted in the daily capture of the wallabies.

\section{References}

Berde, B. \& Boissonnas, R.A. (1968) Basic pharmacological properties of synthetic analogues and homologues of the neurohypophysial hormones. Hand. exp. Pharm. 23, 802-870.

Chauvet, M.Y., Hurpet, D., Chauvet, J. \& Archer, R. (1980) Phenypressin (Phe ${ }^{2}$-Arg ${ }^{8}$ vasopressin), a new neurohypophysial peptide found in marsupials. Nature, Lond. 287, 640-642.

Collie, A. (1830) On some particulars connected with the natural history of the kangaroo. Zool. J. 5, 238-241.

Ferguson, D.R. \& Heller, H.H. (1965) Distribution of neurohypophysial hormones in mammals. J. Physiol., Lond. 180, 846-863.

Griffiths, M., McIntosh, D.L. \& Leckie, R.M.C. (1972) The mammary glands of the Red Kangaroo with observations on the fatty acid components of the milk triglycerides. J. Zool., Lond. 166, 265-275.

Gross, R. \& Bolliger, A. (1959) Composition of milk of the marsupial Trichosurus vulpecula. Am. J. Dis. Chilh. 98, 102-109.

Harris, G.W., Manabe, Y. \& Ruf, K.B. (1969) A study of the parameters of electrical stimulation of myelinated fibres in the pituitary stalk. J. Physiol., Lond. 203, 67-81.

Kirkpatrick, T.H. \& Johnson, P.M. (1969) Studies of Macropodidae in Queensland. 7. Age estimation and reproduction in the agile wallaby Wallabia agilis (Gould). Qd. J. Agric. Anim. Sci. 26, 691-698.

Lemon, M. \& Barker, S. (1967) Changes in milk composition of the Red Kangaroo Megaleia rufa (Desmarest) during lactation. Aust. J. exp. Biol. med. Sci. 45, 213-219.
Lincoln, D.W. \& Renfree, M.B. (1981) Milk ejection in a marsupial, Macropus agilis. Nature, Lond. 289, 504-506.

Lincoln, D.W., Hill, A. \& Wakerley, J.B. (1973) The milk-ejection reflex of the rat: an intermittent function not abolished by surgical levels of anaesthesia. J. Endocr. 57, 459-476.

Merchant, J.C. (1976) Breeding biology of the agile wallaby, Macropus agilis (Gould) (Marsupialia: Macropodidae) in captivity. Aust. Wildl. Res. 3, 93-103.

Merchant, J.C. \& Sharman, G.B. (1966) Observations on the attachment of marsupial pouch young to the teats and on the rearing of pouch young by foster-mothers of the same or different species. Aust. J. Zool 14, 593-609.

Morgan, J. (1833a) A description of the mammary organs of the kangaroo. Trans. Linn. Soc. Lond. 16, 61-84.

Morgan, J. (1833b) A further description of the anatomy of the mammary organs of the kangaroo. Trans. Linn. Soc. Lond. 16, 455-463.

Renfree, M.B. (1979) Initiation of development of diapausing embryo by mammary denervation during lactation in a marsupial. Nature, Lond. 278, 459551.

Sharman, G.B. \& Calaby, J.H. (1964) Reproductive behaviour in the Red Kangaroo, Megaleia rufa, in captivity. CSIRO Wildl. Res. 9, 58-85.

Sharman, G.B. \& Pilton, P.E. (1964) The life history and reproduction of the red kangaroo, Megaleia rufa. Proc. zool. Soc. Lond. 142, 29-48. 